\title{
The Aplication of Open Ended Learning Model to Improve Creative Thinking Skills in Mathematics for Elementary School
}

\section{Alya Rahmawati Aziza}

Sebelas Maret University

alyarahmawatiaziza.ara@gmail.com

\section{Article History}

received 30/4/2021

\begin{abstract}
The purpose of the research to explain creative thinking skills of 4th grade students to solving the angle measurement material by applying the open ended learning model. This research is Classroom Action Research with three cycles. The research subjects were 34 in 4 th grade students of SD Negeri Karangasem 1 No. 61 in the 2020/2021 academic year. The data were collected with interviews, observations, essay test, and documentation. They were analysed using statistic descriptive and interactive analysis. The initial conditions of creative thinking skills of 4th grade students showed 11, $8 \%$ classically. The first cycle began with the first learning classified as high based on the percentage in the creative category of $29 \%$ in classical. The research continued with the second cycle showed $64,7 \%$ in classical. The third cycle was 82 , $4 \%$ in classical. This study is a fundamental exploration to apply numerical learning models dependent on open finished in improving creativity reasoning abilities.
\end{abstract}

Keywords: Creative thinking skills, open ended learning model, angle measurement

\begin{abstract}
Abstrak
Penelitian ini bertujuan untuk menjelaskan keterampilan berpikir kreatif siswa kelas IV dalam menyelesaikan materi pengukuran sudut dengan menerapkan model pembelajaran open ended. Penelitian ini merupakan Penelitian Tindakan Kelas dengan tiga siklus. Subjek penelitian ini adalah 34 siswa kelas 4 SD Negeri Karangasem 1 No. 61 Tahun Pelajaran 2020/2021. Pengumpulan data dilakukan dengan wawancara, observasi, tes essay, dan dokumentasi. Analisis data menggunakan analisis statistik deskriptif dan analisis interaktif. Kondisi awal kemampuan berpikir kreatif siswa kelas IV secara klasikal menunjukkan $11,8 \%$. Siklus I dimulai dengan pembelajaran I tergolong tinggi berdasarkan persentase pada kategori kreatif sebesar 29\% secara klasikal. Penelitian dilanjutkan dengan siklus II menunjukkan 64, 7\% secara klasikal. Siklus III secara klasikal 82, 4\%. Penelitian ini merupakan penelitian pendahuluan untuk menerapkan model pembelajaran matematika berbasis open ended dalam meningkatkan kemampuan berpikir kreatif.
\end{abstract}

Kata kunci: Keterampilan berpikir kreatif, model pembelajaran open ended, pengukuran sudut 


\section{PENDAHULUAN}

Perkembangan pendidikan pada era digital saat ini dihadapkan pada kecakapan yang perlu dimiliki pada abad 21 diantaranya learning and innovation skills yang mencakup keterampilan berpikir kreatif-inovasi, keterampilan berpikir kritis \& pemecahan masalah, serta komunikasi \& kolaborasi; Information, media, and technology skills yang mencakup literasi informasi,media, dan teknologi, life and career skills mencakup fleksibilitas \& kemampuan beradaptasi, inisiatif \& pengarahan diri sendiri, keterampilan sosial \& lintas budaya, produktivitas \& akuntabilitas, kepemimpinan \& tanggung jawab (Lee, State, \& Carpenter, 2017; Mehmet Ciğerci, 2020; Scott, 2015). Keterampilan berpikir kreatif sangat diperlukan dalam proses pembelajaran karena peserta didik dapat mengungkapkan pikiran mereka secara bebas dan menemukan serta menghasilkan pengetahuan. Keterampilan berpikir kreatif merupakan proses merasakan kesulitan, masalah, kesenjangan dalam informasi yang menjadi keinginan dari individu untuk menemukan produk atau solusi dari hasil imajinasinya (Ozgenel, 2018; Senel \& Bağçeci, 2019; Wojciehowski \& Ernst, 2018). Faktanya, kebanyakan individu menghasilkan ide-ide kreatif setiap hari dan setiap saat, tetapi ide-ide kreatif yang tidak diimplementasikan tidak banyak berarti. Mata pelajaran matematika memerlukan keterampilan tersebut dalam mengolah suatu informasi yang bertujuan untuk mengkonsolidasikan mata pelajaran matematika lebih dari untuk mengembangkan keterampilan berpikir peserta didik (Aljarrah, 2020; Coşkun Çelik \& Özdemir, 2020; Leikin \& Elgrably, 2019; Surya, Marmoah, Sularmi, \& Istiyati, 2018). Berdasarkan pengembangan yang dilakukan terdapat tiga indikator keterampilan berpikir kreatif, yaitu kelancaran (fluency), keluwesan (flexibility), serta kebaruan (novelty) (Siswono, 2018)(Wojciehowski \& Ernst, 2018). Fluency merujuk pada keberagaman pemikiran dalam menghasilkan ide atau gagasan. Flexibility merujuk pada keberagaman pengkategorian permasalahan yang berbeda-beda. Novelty merujuk pada orisinalitas dalam menyelesaikan suatu hal dengan cara yang berbeda.

Berpikir itu sangat penting untuk semua individu dalam kehidupan sehari-hari, dan pemikiran matematis sangat penting untuk memahami dunia sekitar kita. Dalam merencanakan dan melaksanakan pembelajaran, guru dan calon guru perlu meningkatkan pemikiran matematis peserta didik mereka, pemecahan masalah, penalaran dan disposisi keterampilan berpikir kritis. Namun, mereka yang tidak mengembangkan pemikirannya keterampilan tidak akan dapat menggunakan pengetahuan dalam perbendaharaan bahasa mereka karena aktivitas mental terbesar akan untuk menghafal dan mencoba mengingat apa yang telah mereka hafal (Armandita, Wijayanto, Rofiatus, \& Susanti, 2017; Coşkun Çelik \& Özdemir, 2020; M. Schoevers, Eveline, 2019). Faktanya, di SD Negeri Karangasem 1 No. 61 peserta didik kelas IV masih kurang dalam mengasah kemampuan problem solving sehingga penemuan ide atau gagasan juga terhambat dan sulit untuk mengembangkan kebaruan. Akibatnya, peserta didik hanya terpaku dengan satu jawaban saja dan belum tertantang untuk menyelesaikan masalah dengan berbagai cara lebih dari satu. Hal ini menjadikan kurang terasahnya keterampilan berpikir kreatif pada matematika khusunya.

Tindak lanjut dari hasil wawancara maupun observasi, serta tes pratindakan yang sudah terlaksana nantinya dapat diketahui kecakapan awal peserta didik mengenai keterampilan berpikir kreatif pada materi pengukuran sudut ini. Hasil data tes pratindakan menunjukkan sebesar $11,8 \%$ peserta didik yang mencapai kreatif kategori tinggi. Hasil tersebut dapat dilihat keterampilan berpikir kreatif yang belum maksimal. Beberapa beberapa penelitian menjelaskan bahwa keterampilan berpikir kreatif peserta didik rendah, seperti pada penelitian Rahmazatullaili (Rahmazatullaili, Zubainur, \& Munzir, 2017) dengan menggunakan model pembelajaran PBL dapat meningkatkan keterampilan berpikir kreatif, dan penelitian Adi S. (Muhammad \& 
Atmojo, 2017) penggunaan model pembelajaran PjBL dapat meningkatkan keterampilan berpikir fluency dan flexibility. Terjadinya peningkatan dalam keterampilan berpikir kreatif peserta didik dapat dibantu dengan inovasi-inovasi penggunaan model pembelajaran tersebut.

Keterampilan berpikir kreatif ini disadari sangat penting dalam pembelajaran, sehingga diharapkan dapat melatih inovasi dalam keragaman penyelesain masalah berupa ide atau gagasan berpikir peserta didik. Model pembelajaran Open Ended ini lebih menegaskan pada pengembangan dalam mengemukakan ide, dalam kreativitasnya, dalam berkomunikasi, dan dalam berinteraksi (Margaret Carparo, A. An, Ma, A., \& Harbaugh, 2012; Wahyu Ningsih, Budianti, \& Sumirat, 2020). Guru sebagai fasilitator peserta didik, sebaliknya peserta didik diharapkan dapat memiliki peran aktif serta keberanian mengungkapkan ide atau gagasan untuk dapat solutif ditinjau dari berbagai masalah yang ada. Hal ini selaras dengan Betty $(A, 2015)$ bahwa dalam peningkatan kualitas suatu kegiatan belajar di kelas dengan disajikannya masalah yang dapat ditemukannya jawaban lebih dari satu, sehingga peserta didik dapat berkesempatan untuk mengasah dan menyelesaikan masalah dengan beberapa teknik atau cara.

Berdasarkan uraian di atas, maka penelitian ini bertujuan untuk menganalisis keterampilan berpikir kreatif pada peserta didik kelas IV pada materi pengukuran sudut. Manfaat dari penerapan model pembelajaran Open Ended ini dapat meningkatkan kreatifitas peserta didik dalam menyelesaikan soal. Hasil penelitian digunakan sebagai langkah dalam pengembangan model pembelajaran yang inovatif untuk meningkatkan keterampilan berpikir kreatif.

\section{METODE}

Penelitian ini dilaksanakan di SD Negeri Karangasem 1 No. 61 yang dilakukan mulai dari bulan Februari hingga Juni 2021. Subjek penelitian ini adalah 34 peserta didik kelas IV yang terdiri dari 16 laki-laki dan 18 perempuan. Penelitian tindakan kelas ini dilakukan secara daring (dalam jaringan). Data hasil penelitian berupa data kualitatif bersumber pada penerapan model pembelajaran open ended dan data kuantitatif bersumber pada hasil tes keterampilan berpikir kreatif matematika materi pengukuran sudut. Teknik pengumpulan data menggunakan observasi, wawancara, tes, dan analisis dokumen. Validitas data berupa triangulasi teknik dan sumber. Teknik analisis data, yaitu pengumpulan data, reduksi data, penyajian data, dan penarikan simpulan.

Prosedur penelitian ini menggunakan model penelitian tindakan kelas yang terdapat empat tahapan, yaitu perencanaan, pelaksanaan, observasi, dan refleksi. Indikator kinerja penelitian ini adalah penerapan model pembelajaran open ended pada pembelajaran matematika materi pengukuran sudut $(\mathrm{KKM}=75)$ ditargetkan mencapai $80 \%$ dari jumlah peserta didik.

\section{HASIL DAN PEMBAHASAN}

Penelitian ini dilakukan dalam tiga siklus dan pada satu siklus terdapat satu pertemuan. Langkah-langkah model pembelajaran open ended yang sudah dilaksanakan dalam tiga siklus yaitu: (a) penyajian masalah, (b) mengkonstruksi masalah, (c) mengeksplorasi masalah, (d) membuat kesimpulan. Langkah pembelajaran tersebut berdasar pada teori menurut Huda (2014), Isrok'atun \& Rosmala (2018), dan Kosyvas (2015).

Hasil observasi penerapan model pembelajaran open ended mengalami kenaikan pada setiap siklusnya sehingga dapat mencapai indikator kinerja penelitian sebesar $80 \%$ dari jumlah peserta didik terlihat pada gambar 1 . 


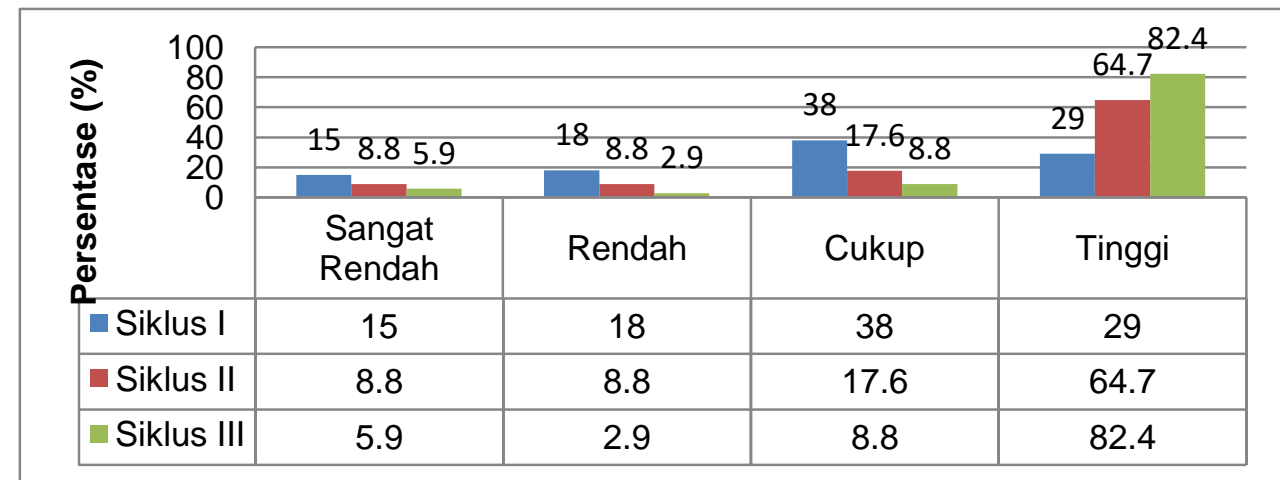

Gambar 1. Hasil Keterampilan Berpikir Kreatif pada Materi Pengukuran Sudut Siklus I sampai III

Berdasarkan gambar 1 dapat diketahui bahwa persentase penerapan model pembelajaran open ended mengalami kenaikan.

Tabel 1. Perbandingan Antarsiklus Keterampilan Berpikir Kreatif pada Materi Pengukuran Sudut

\begin{tabular}{lccc}
\hline \multicolumn{1}{c}{ Keterangan } & \multicolumn{3}{c}{ Siklus } \\
\cline { 2 - 4 } & I & II & III \\
\hline Nilai Terendah & 0 & 0 & 0 \\
Nilai Tertinggi & 88,89 & 88,89 & 100 \\
Nilai Rerata & 58,06 & 67,03 & 78,57 \\
Ketercapaian & $29 \%$ & $64,7 \%$ & $82,4 \%$ \\
\hline
\end{tabular}

Berdasarkan tabel 1 dapat dilihat bahwa hasil tes keterampilan berpikir kreatif peserta didik meningkat dari siklus I ke siklus III. Siklus I nilai tertinggi yang diperoleh sebesar 88,89, nilai terendah sebesar 0 , nilai rerata sebesar 58,06 dengan peserta didik kreatif sejumlah 10 dan tidak kreatif sejumlah 24 peserta didik. Siklus II nilai tertinggi sebesar 88,89 , nilai terendah sebesar 0 , nilai rerata sebesar 67,03 dengan peserta didik kreatif sejumlah 22 dan tidak kreatif sejumlah 12 peserta didik. Siklus III nilai tertinggi sebesar 100 , nilai terendah sebesar 0 , nilai rerata sebesar 78,57 dengan peserta didik kreatif sejumlah 28 dan tidak kreatif sejumlah 6 peserta didik.

Penelitian tersebut membuktikan bahwa adanya peningkatan hasil tes keterampilan berpikir kreatif peserta didik dari siklus I ke siklus III. Hal tersebut selaras dengan pendapat Betty Biliya (2015) bahwa model open ended dapat mengembangkan keterampilan serta kreativitas dalam memecahkan suatu permasalahan.

\section{SIMPULAN}

Berdasarkan rumusan masalah, hasil penelitian, dan pembahasan dalam penelitian ini, dapat diambil kesimpulan sebagai berikut: (1) penerapan model pembelajaran open ended untuk meningkatkan keterampilan berpikir kreatif pada pembelajaran matematika materi pengukuran sudut peserta didik kelas IV SD Negeri Karangasem 1 No. 61 Laweyan Surakarta tahun ajaran 2020/2021 dilaksanakan dengan langkah-langkah: (a) penyajian masalah, (b) mengkonstruksi masalah, (c) mengeksplorasi masalah, (d) menarik kesimpulan. (2) penerapan model pembelajaran open ended dapat meningkatkan keterampilan berpikir kreatif pada pembelajaran matematika materi pengukuran sudut peserta didik kelas IV SD Negeri Karangasem 1 No. 61 Laweyan Surakarta tahun ajaran 2020/2021.

Persentase ketuntasan pada siklus I sejumlah 29\%, siklus II sejumlah 64,7\%, dan siklus III sejumlah $82,4 \%$. (3) kendala yang muncul dalam pembelajaran yaitu: (a) 
guru kurang memberikan pertanyaan pemantik untuk memancing keaktifan peserta didik; (b) peserta didik belum termotivasi untuk mengajukan pertanyaan atau ide atau gagasan terkait; (c) beberapa peserta didik belum secara tepat dalam membaca busur derajat; (d) guru hanya bisa menunjuk beberapa peserta didik untuk menunjukkan hasil pemikirannya karena waktu yang terbatas dan kendala jaringan; (e) beberapa peserta didik belum maksimal dalam mengasah ide kreatifnya sehingga menghambat dalam menjawab soal. Adapun solusinya yaitu: (a) guru dapat mempersiapkan beberapa pertanyaan pemantik kepada peserta didik; (b) guru memberikan motivasi dorongan kepada peserta didik untuk dapat mengajukan beberapa pertanyaan atau ide ataupun gagasannya dengan percaya diri; (c) guru dapat memberikan materi tambahan kepada peserta didik; (d) guru dapat memantau peserta didik lain melalui kirim pesan whatsapp setelah pembelajaran selesai untuk mengetahui kesulitan yang dihadapi atau sejauh mana peserta didik dapat memahami materi; (e) guru dapat memberikan beragam contoh yang dapat ditemui dalam kehidupan sehari-hari peserta didik agar mudah dalam menyelaraskan dengan apa yang mereka pelajari.

Keterkaitan dengan hasil penelitian ini, peneliti mengajukan saran sebagai berikut: (1) hendaknya peserta didik lebih fokus, percaya diri, dan berani dalam menyampaikan idea tau gagasan, (2) hendaknya guru dapat variatif dalam menerapkan model pembelajaran yang bisa disesuaikan dan untuk mengurangi kejenuhan peserta didik, (3) peningkatan dalam penerapan model-model pembelajaran yang inovatif dan variatif dapat dipilih sebagai salah satu cara memperbaiki mutu pendidikan, dan (4) hendaknya peneliti selanjutnya dapat mengkaji lebih banyak sumber referensi agar penelitian dapat lebih lengkap.

\section{DAFTAR PUSTAKA}

A, B. B. (2015). Penerapan Model Open Ended Untuk Meningkatkan Keterampilan Proses dan Hasil Belajar Siswa Kelas V SDN 1 Repaking - Wonosegoro Boyolali. Scholaria, 5(1), 78-91.Aljarrah, A. (2020). Describing Collective Creative Acts in a Mathematical Problem-Solving Environment. Journal of Mathematical Behavior, 60, 1-14. https://doi.org/https://doi.org/10.1016/j.jmathb.2020.100819Armandita, P.,

Coşkun Çelik, H., \& Özdemir, F. (2020). Mathematical Thinking as a Predictor of Critical Thinking Dispositions od Pre-service Mathematics Teachers. International Journal of Progressive Education, 16(4), 81-98. https://doi.org/https://doi.org/10.29329/ijpe.2020.268.6

Huda, M. (2014). Model-Model Pengajaran dan Pembelajaran: Isu-Isu Metodis dan Paradigmatis. Yogyakarta: Pustaka Pelajar.Isrok'atun, \& Rosmala, A. (2018). Model-Model Pembelajaran Matematika. Jakarta: Bumi Aksara.

Kosyvas, G. (2015). International Journal of Mathematical Levels of arithmetic reasoning in solving an open-ended problem, (August). https://doi.org/10.1080/0020739X.2015.1072880

Lee, S., State, C., \& Carpenter, R. (2017). Creative Thinking for 21st Century Composing Practices : Creativity Pedagogies across Disciplines.

Leikin, R., \& Elgrably, H. (2019). Problem Posing Through Investigations for the Development and Evaluation of Proof-related Skills and Creativity Skills of Prospective high school mathematics teachers. International Journal of Education Research, 1-13. https://doi.org/https://doi.org/10.1016/j.ijer.2019.04.002M.

Margaret Carparo, M., A. An, S., Ma, T., A., F. R.-C., \& Harbaugh, A. (2012). An Investigation of Preservice Teacher's Use of Guess and Check In Solving a Semi Open-Ended Mathematics Problem. The Journal of Mathematical Behavior, 31, 105-116. https://doi.org/http://dx.doi.org/10.1016/j.mathb.2011.10.002 
Mehmet Ciğerci, F. (2020). Primary School Teacher Candidates and 21st Century Skills. International Journal of Progressive Education, 16(2), 157-174. https://doi.org/https://doi.org/10.29329/ijpe.2020.241.11

Muhammad, A. S., \& Atmojo, I. R. W. (2017). Peningkatan Keterampilan Fluency Melalui Penerapan Model Pembelajaran Project Based Learning (PjBL) Pada Pembelajaran IPA Di Sekolah Dasar. Jurnal Pendidikan Dasar, 6(1), $42-47$.

Ozgenel, M. (2018). Modeling the Relationships between School Administrators Creative and Critical Thinking Dispositions with Decision Making Styles and Problem. Educational Science: Theory \& Practice, 18(3), 673-700. https://doi.org/10.12738/estp.2018.3.0068Rahmazatullaili, Zubainur, C. M., \& Munzir, S. (2017). Kemampuan berpikir kreatif dan pemecahan masalah siswa melalui penerapan model project based learning. Jurnal Tadris Matematika, 10(2), 166-183.

Schoevers, Eveline, et all. (2019). Promoting Pupils' Creative Thinking in Primary School Mathematics: A Case Study. Thinking Skills and Creativity, 31, 323-334. https://doi.org/https://doi.org/10.1016/j.tsc.2019.02.003

Scott, C. L. (2015). The Futures of Learning 3: What Kind of Pedagogies For The 21st Century? (Education Rasearch and Foresight Working Papers Series, No. 15). Paris.

Senel, M., \& Bağçeci, B. (2019). Development of Creative Thinking Skills of Students Through Journal Writing. International Journal of Progressive Education, 15(5), 216-237. https://doi.org/https://doi.org/10.29329/ijpe.2019.212.15

Siswono, T. Y. E. (2018). Pembelajaran Matematika Berbasis Pengajuan dan Pemecahan Masalah Fokus Pada Berpikir Kritis dan Berpikir Kreatif. Bandung: PT Remaja Rosdakarya.

Surya, A., Marmoah, S., Sularmi, \& Istiyati, S. (2018). Learning trajectory to improve students ' critical thinking skill in graphing and statistics concept at elementary education Learning Trajectory to Improve Students ' Critical Thinking Skill in Graphing and Statistics Concept at Elementary Education. AIP Conference Proceedings, 020091(September), 1-6. https://doi.org/10.1063/1.5054495

Wahyu Ningsih, E., Budianti, Y., \& Sumirat, F. (2020). Model Pembelajaran Open Ended sebagai Solusi untuk Memaksimalkan Hasil Belajar Matematika Siswa SD. JMIE: Journal of Madrasah Ibtidaiyah Education, 4(2), 234-247. https://doi.org/http://dx.doi.org/10.32934/jmie.v4i2.192

Wijayanto, E., Rofiatus, L., \& Susanti, A. (2017). Analisis Kemampuan Berpikir Kreatif Pembelajaran Fisika Di Kelas XI MIA 3 SMA Negeri 11 Kota Jambi. Jurnal Penelitian IImu Pendidikan, 10.

Wojciehowski, M., \& Ernst, J. (2018). Creative by Nature: Investigating the Impact of Nature Preschools on Young Children 's Creative Thinking Mandi Wojciehowski Great Lakes Aquarium , USA Julie Ernst. International Journal of Early Childhood Environmental Education, 6(1), 3-20. 